\title{
Taxa de lucro e acumulação de capital no Brasil: concepções teóricas, análise histórica e relação de causalidade
}

Profit rate and capital accumulation in Brazil: theoretical conceptions, historical analysis and causal relationship

Henrique de Abreu Grazziotin a Ana Paula Fornari ${ }^{b}$ Adalmir Antonio Marquetti ${ }^{c}$

\begin{abstract}
Resumo: O presente trabalho analisa a relação entre a taxa de lucro e a acumulação de capital a partir de perspectivas teórica e empírica. Na teórica, discutimos as principais abordagens sobre o papel da lucratividade na análise macroeconômica, com ênfase na economia política marxiana. Na empírica, apresentamos uma breve descrição histórica da evolução da tax a de lucro e da taxa de acumulação para o Brasil entre 1953 e 2017, avaliando seus componentes por meio da decomposição de Weisskopf (1979). Por fim, aplicamos o procedimento de Toda e Yamamoto (1995) para testar a hipótese de não causalidade de Granger nas variáveis taxa de lucro e taxa de acumulação de capital. Os resultados são consistentes com a presença de causalidade de Granger unidirecional da taxa de lucro para a taxa de acumulação no Brasil entre 1953 e 2017.
\end{abstract}

Palavras-chave: Taxa de Lucro; Marxismo; Acumulação de Capital; Causalidade Granger. Classificação JEL: B51, C10, E22

\begin{abstract}
This paper analyzes the relationship between profit rate and capital accumulation from both theoretical and empirical perspectives. We discuss the main approaches to the role of profitability in macroeconomic analysis, with emphasis on the Marxian political economy. We present a brief historical description of the profit rate and the capital accumulation rate for Brazil between 1953 and 2017, evaluating their components through Weisskopf's (1979) decomposition. We also apply Toda and Yamamoto's (1995) procedure to test Granger's hypothesis of non-causality between profit rate and capital accumulation rate. Granger noncausality tests support unidirectional causation from profit rate to capital accumulation rate in Brazil between 1953 and 2017.
\end{abstract}

Keywords: Profit Rate; Marxism; Capital Accumulation; Granger Causality

\footnotetext{
${ }^{\text {a }}$ Bacharel em Ciências Econômicas pela Universidade Federal do Rio Grande do Sul (FCE/UFRGS). Mestre em Economia (área de concentração em Economia do Desenvolvimento) pelo PPGE/UFRGS. Doutorando em Economia pela University of Massassuchets at Amherst (UMass)Email: henrique.grazziotin@ gmail.com.

${ }^{\mathrm{b}}$ Bacharela em Ciências Econômicas pela Pontifícia Universidade Católica do Rio Grande do Sul (PUC-RS). Email: anapfornari@gmail.com.

${ }^{c}$ Professor Titular da Pontifícia Universidade Católica do Rio Grande do Sul e do Programa de Pós-Graduação em Economia do Desenvolvimento (PPGE/PUC-RS). Email: $\underline{\text { aam@ @ucrs.br. }}$
} 


\section{Introdução}

O presente trabalho analisa a relação entre taxa de lucro e acumulação de capital dos pontos de vista teórico e empírico. Na perspectiva teórica, investigamos as diversas vertentes de pensamento econômico sobre o tema, com ênfase na abordagem marxiana. $\mathrm{Na}$ perspectiva empírica, realizamos uma breve descrição histórica da taxa de lucro e da taxa de acumulação no Brasil entre 1953 e 2017 e realizamos um teste de causalidade de Granger entre estas duas séries.

A taxa de lucro, dentro da abordagem da economia política, consiste em uma relação essencial para a compreensão da dinâmica capitalista e de seus diferentes estágios, compreendendo não só o seu dinamismo macroeconômico, como também as suas transformações estruturais. Outras abordagens teóricas, por sua vez, não consideram a rentabilidade e sua evolução como um elemento central da dinâmica econômica. Este trabalho aborda essa divergência e traz elementos empíricos que sustentam a relevância da análise da taxa de lucro para a compreensão da economia brasileira. Alguns dos demais trabalhos já realizados no escopo dessa abordagem teórica para o Brasil são aqui sinteticamente apresentados, com o intuito de apresentar sua a relevância e suas contribuições. Além disso, realizamos uma análise econométrica para testar a precedência temporal entre taxa de lucro e acumulação, investigando a relação de causalidade temporal entre estas duas variáveis.

Para isso, a discussão deste trabalho está organizada da seguinte maneira para além da introdução: Na seção dois, apresentamos as principais perspectivas teóricas sobre acumulação de capital e taxa de lucro, contrastando a relevância da lucratividade na economia política marxiana com as demais abordagens teóricas, que tratam a lucratividade como elemento passivo da dinâmica macroeconômica. Na seção três, apresentaremos uma breve descrição histórica da evolução da taxa de lucro e da taxa de acumulação para o Brasil entre 1955 e 2017, avaliando seus componentes por meio da decomposição de Weisskopf (1979). Na quarta seção, apresentamos os testes de não causalidade de Granger entre as variáveis taxa de lucro e taxa de acumulação de capital, para qual foi aplicada a metodologia de Toda e Yamamoto (1995). Por fim, apresentamos a conclusão do trabalho.

\section{Concepções Teóricas sobre o Papel da Lucratividade no Investimento Produtivo}

Quando se trata de análise macroeconômica, principalmente em relação aos ciclos de negócios, ou seja, flutuações econômicas de expansão e contração da atividade econômica agregada que acontecem de forma recorrente nas economias capitalistas, as diversas escolas do pensamento econômico têm interpretações distintas sobre os determinantes desses movimentos. Apesar de haver diversas interpretações teóricas sobre 
as causas dos ciclos de negócios, é possível categorizar esses trabalhos em duas principais vertentes: as teorias endógenas e exógenas.

As teorias exógenas dos ciclos de negócios concebem os ciclos como resultado de "choques aleatórios", ou seja, eventos externos e imprevistos que interferem no equilíbrio da economia e cuja origem não remonta ao sistema econômico. Alguns exemplos de choques aleatórios poderiam ser fenômenos naturais, como desastres ambientas, seca ou pragas, ou então fenômenos sociais, como o levante de movimentos sociais, golpes, escândalos políticos, etc. Choques aleatórios são fenômenos concebidos como essencialmente alheios ao sistema econômico e que não podem ser controlados ou previstos. Assim, essas teorias apontam que há uma trajetória de equilíbrio macroeconômico natural que é desestabilizada por algum evento desse tipo, causando as flutuações. Desconsiderando esses eventos, a economia de determinado país tenderia a permanecer em trajetória de equilíbrio estável. Essa é a principal concepção de ciclos nas abordagens de matriz neoclássica.

As teorias endógenas, por sua vez, buscam explicar as flutuações do produto agregado por meio do estudo de variáveis econômica específicas, entendidas como responsáveis por determinar a dinâmica do ciclo, como, por exemplo, salários, investimento e taxa de lucro. Essas abordagens teóricas não assumem uma trajetória de equilíbrio inerentemente estável, mas uma dinâmica interna ao sistema, que ocasiona as flutuações e eventualmente crises. As variáveis determinantes para o ciclo são consideradas componentes-chaves para a macroeconomia, já que geralmente podem ser monitoradas e até mesmo previstas.

$\mathrm{Na}$ abordagem teórica da economia política clássica, e principalmente em Marx, a lucratividade é o motor essencial da dinâmica capitalista, e a análise da evolução da taxa de lucro é fundamental para a compreensão da dinâmica macroeconômica. Para compreender o porquê disso, essa seção sistematiza as principais concepções teóricas existentes sobre o lucro e seu papel na explicação da dinâmica econômica descrita por cada uma dessas concepções. Além de discutir como cada abordagem compreende o lucro, discutimos também a relação teórica entre lucro e investimento, compreendido aqui como parte essencial da acumulação de capital. Tanto em relação ao crescimento econômico, na ampliação do produto potencial, como na explicação das flutuações, a análise da evolução do investimento é essencial.

Dividimos aqui a exposição entre as abordagens teóricas em que a lucratividade cumpre um papel passivo, no sentido de ser apenas determinada por outras variáveis e não ser vista como elemento determinante, e as abordagens nas quais a lucratividade é compreendida como elemento central da dinâmica capitalista. 


\subsection{Abordagens Teóricas nas quais a Taxa de Lucro tem Papel Passivo}

Inicialmente, trataremos das abordagens teóricas em que o lucro não tem papel central e determinante. Enquadra-se nessa classificação a abordagem neoclássica, na qual o lucro é meramente a remuneração do fator de produção "capital" e um preço que cumpre a função de sinalização para os agentes racionais da alocação mais eficiente desse fator.

Também se enquadram as abordagens keynesiana e kaleckiana, nas quais a determinação do lucro ocorre a partir da demanda efetiva, por meio da determinação da renda a partir das decisões de gasto e do lucro como consequência desse processo.

A concepção neoclássica do lucro pode ser descrita na teoria da distribuição de John Bates Clark, concebida ao final do século XIX, que dá ao lucro e aos salários uma fundamentação teórica coerente com os demais preceitos dessa abordagem. Antes disso, as diversas justificativas históricas dadas para que indivíduos pudessem obter renda na forma de lucro limitaram-se a argumentos como do comportamento abstêmio, em que o indivíduo tem direito ao lucro por abdicar de consumir, ou do risco de ganho ou perda associado ao empreendimento capitalista. A teoria de Clark se baseia na remuneração dos fatores de produção em contexto de maximização de lucros, na qual a remuneração dos fatores capital e trabalho corresponde a sua produtividade marginal, a qual representa a sua devida parcela de contribuição na produção. ${ }^{1}$

Clark formulou sua teoria neoclássica da firma a partir da possibilidade de combinar insumos não necessariamente em proporções fixas no processo de produção. Assim, com a possibilidade de variar a quantidade de trabalho em relação ao capital, derivou o conceito de produto marginal do trabalho, observando que, considerando um nível constante de capital, o acréscimo no número de trabalhadores implicaria na variação decrescente da produtividade marginal do trabalho. Essa medida permitiria ao capitalista otimizar sua produção e, consequentemente, seus lucros. ${ }^{2}$

Uma famosa crítica desta abordagem teórica é a "controvérsia de Cambridge", que consiste no problema de agregação de quantidades de capital. O nível ótimo de produção combina uma determinada quantidade física de trabalho e capital que serão usados para produzir uma determinada quantidade física de bens de consumo. No entanto, o capital é composto por diversos elementos fisicamente heterogêneos, apresentando assim uma

\footnotetext{
${ }^{1}$ A implicação lógica que resulta dessa abordagem é conveniente para os teóricos que se dedicaram a fazer a defesa ideológica do capitalismo de livre mercado, bem como a defesa da inexistência do conflito distributivo na sociedade (HUNT, 2013).

${ }^{2}$ Quando se é considerado o produto marginal do trabalho e o preço do produto como receita, e o preço do trabalho (salário) como despesa, é possível obter o quanto será adicionado ao lucro da firma com a contratação de mais um operário. O ponto ótimo, ou seja, a maximização do lucro acontece quando a firma contrata trabalhadores apenas até o ponto em que o valor do produto marginal do trabalho iguala o salário. Considerando que a firma está sujeita à concorrência e que o preço do trabalho é determinado no mercado de trabalho, o capitalista não estaria exercendo qualquer influência sobre o preço do trabalho ou sobre o preço da mercadoria por ele vendida, sendo tomados esses valores como dados.
} 
dificuldade teórica para a agregação do capital e para a mensuração da sua produtividade marginal. ${ }^{3}$

Além da remuneração do fator capital, para a concepção neoclássica, o lucro é o preço que sinaliza para os agentes racionais a alocação eficiente do capital, gerando os incentivos para mobilidade de capitais entre setores ou países conforme os diferenciais de rentabilidade, associados à escassez desse fator de produção. Essa perspectiva é, em certo sentido, análoga à concepção clássica de lucro como elemento que gera investimentos em diferentes setores a partir do diferencial de rentabilidade, porém fundamentalmente distinta em seus preceitos teóricos e na dinâmica na qual esse processo de "equilíbrio" é obtido. ${ }^{4}$

A perspectiva neoclássica entende a remuneração do fator capital como um custo de oportunidade, já que o empresário estaria abrindo mão do uso desses recursos para investir e receber juros no futuro. Como argumenta Shaikh (2011) sobre a concepção da remuneração do fator capital na teoria neoclássica, os custos de produção já são definidos incluindo um "custo de oportunidade" compreendendo os juros equivalentes ao estoque de capital. Dessa forma, não haveria nenhum excedente decorrente da produção, pois, em equilíbrio, cada fator de produção recebe exatamente aquilo que contribui na geração de valor. A existência de lucro acima do juro normal sobre o capital seria uma anomalia alocativa nessa abordagem, pois, no contexto de equilíbrio, a remuneração do capital é apenas o custo de oportunidade relacionado à remuneração desse fator de produção, não existindo qualquer excedente possível.

Em relação ao investimento na concepção neoclássica, grande parte das teorias do investimento explicam o conceito como sendo uma resposta ao nível de estoque de capital desejado, como uma escolha racional condicionada ao nível de demanda esperado pelo produto e custos de produção. Níveis mais altos de demanda por produto levariam as firmas a optar por um estoque maior de capital. Ao mesmo tempo, diversas teorias neoclássicas ressaltam a necessidade de poupança prévia como uma condição para o investimento, e analisam a taxa de poupança como uma medida da capacidade de investimento de determinada economia nacional. Partindo do princípio de fundos emprestáveis e de que a

\footnotetext{
${ }^{3}$ Hunt (2013) exemplifica essa questão da seguinte forma: “A medida universal com a qual os capitalistas medem seu capital é o valor, quer dizer, cada item é contado somando seu preço aos preços dos outros itens que constituem o estoque de capital. Embora esse método seja perfeitamente apropriado para os capitalistas, que só estão interessados em obter lucros e não em dar uma justificativa intelectual para os lucros, ele é absolutamente inadequado para a teoria da distribuição baseada na produtividade marginal. [...] Não pudemos supor seu valor, a fim de verificar sua produtividade. Se fizermos isso, a produtividade do capital dependerá de seu valor. Contudo, de acordo com a teoria neoclássica, essa linha de causalidade tem de ser invertida: o valor do capital tem de depender de sua produtividade. Por conseguinte, para [...] que se livre da acusação de circularidade intelectual, é necessário haver algum método completamente independente dos preços de quantificação do capital usado na produção" (HUNT, 2013, p. 266).

${ }^{4}$ Duménil e Levy (1993) ressaltam que a concepção clássica de competição é distinta da neoclássica. Enquanto na neoclássica, os preços de equilíbrio ajustam o mercado automaticamente, levando a uma condição de equilíbrio de longo prazo e conforme as dotações dos fatores, a concorrência na economia política clássica é um processo gravitacional em torno do lucro médio, sendo um processo de ajuste e desajuste constante em torno de uma média.
} 
existência desses fundos depende da poupança, maior poupança se refletiria em menor custo do capital, ampliando o investimento.

As diversas vertentes keynesianas apresentam discordância fundamental em relação ao investimento e às concepções das causas de flutuações macroeconômicas. A partir do princípio de demanda efetiva, Keynes ressalta a possibilidade de equilíbrios abaixo do nível de pleno emprego, a primazia das decisões de gastos como elemento central na determinação do nível de emprego e a incerteza fundamental como elemento explicativo das decisões de longo prazo, notadamente o investimento produtivo. Diferentemente da perspectiva neoclássica, na qual há necessidade da poupança prévia para a realização do investimento, Keynes explicou ser a decisão de gasto a causa última para a determinação da renda e da poupança, sendo o investimento a variável mais instável nessa determinação. $\mathrm{Na}$ teoria de Keynes, o investimento é entendido como a principal variável explicativa para a dinâmica macroeconômica do ciclo de negócios (GRANADOS, 2012).

Para Keynes, em contextos de elevada incerteza, será maior a preferência pela liquidez dos agentes, ou seja, preferência por reter ativos líquidos, como dinheiro ou aplicações de alta liquidez, de forma a manter maior flexibilidade em contextos futuros. Isso significa dizer que, quanto mais incerto for o cenário econômico, mais os agentes irão demandar e reter ativos líquidos. ${ }^{5}$ Com isso, adiam-se as decisões de gasto, o que acarreta na possibilidade da não realização da demanda, já que, ao reter moeda, os agentes estão decidindo por não consumir e não realizar gastos de investimento, não demandando produtos. Dessa forma, a incerteza é um fator que pode levar a expectativas de baixa demanda (expectativas “bear”, em inglês), reduzindo investimentos. Como o investimento é a variável volátil da demanda, isso afeta a renda e, consequentemente, a lucratividade.

Por outro lado, em contextos em que a preferência por liquidez se reduz, em que há expectativas positivas quanto à demanda futura (expectativas “bull”, em inglês), o investimento produtivo ocorre em maior magnitude e é determinado pelo que Keynes chama de eficiência marginal do capital e pela taxa de juros. O conceito de eficiência marginal do capital para Keynes significa a taxa de retorno do capital esperada, isso é, a rentabilidade esperada. Por ser uma expectativa de rentabilidade, trata-se de um elemento

\footnotetext{
${ }_{5}^{5}$ Dentre outros motivos pelos quais os agentes demandam moeda está o motivo financeiro e o motivo especulativo. O motivo financeiro equivale ao fluxo monetário necessário para a aquisição de novos equipamentos, diz respeito às incertezas quanto às decisões de investimento produtivo. Já o motivo especulação está relacionado à incerteza quanto ao comportamento futuro da taxa de juros. Os agentes que especulam no mercado também tomam suas decisões de investimento com base nas expectativas em relação à taxa de juros futura e, por esse motivo, também demandam moeda.
} 
subjetivo, dependente da incerteza em relação à demanda futura e da receita a ser obtida. Além disso, depende também do custo do bem de capital. ${ }^{6}$

O investimento também é função dos juros reais, pois a decisão de investimento produtivo é realizada a partir da comparação entre a expectativa marginal do capital em relação à taxa de juros corrente. Dessa forma, o empresário seria capaz de mensurar os custos de oportunidade entre investir nos ativos mais líquidos, remunerados pela taxa de juros, ou nos menos líquidos como o investimento produtivo de capital. A curva da eficiência marginal do capital $(\mathrm{EMgK})$ é uma curva decrescente, pois, conforme o investimento em um dado capital aumenta, a eficiência marginal desse capital diminui. ${ }^{7} \mathrm{O}$ investimento oscila no ciclo de negócios até o ponto em que a eficiência marginal do capital seja igual à taxa de juros praticada no mercado:

[...] a taxa efetiva de investimento corrente só tende a aumentar até o ponto em que não haja mais nenhuma classe de bem de capital cuja eficiência marginal exceda a taxa de juros corrente. Em outras palavras o investimento vai variar até aquele ponta da curva de demanda de investimento em que a eficiência marginal do capital em geral é igual à taxa de juros do mercado (KEYNES, 1996, p. 150).

Conforme apresentado, para Keynes a determinação do investimento é bastante distinta da perspectiva neoclássica, e está baseada nas expectativas de longo prazo, que afetam a eficiência marginal do capital, e no nível de taxa de juros corrente. Esta considera o lucro apenas enquanto expectativa, na realização das decisões de gasto. Pelo princípio da demanda efetiva, são as decisões de gasto que determinam o nível de atividade e, consequentemente, a lucratividade. Assim, ambas perspectivas teóricas colocam a taxa de lucro como um elemento passivo, que é consequência ou da remuneração do fator capital, conforme sua escassez, ou do nível de atividade, conforme as decisões de gasto. A abordagem kaleckiana, que também deriva do princípio da demanda efetiva, guarda esse mesmo princípio na famosa frase "os trabalhadores gastam o que ganham e os capitalistas ganham o que gastam”.

\footnotetext{
6 "A eficiência marginal do capital é definida aqui em termos da expectativa de renda e do preço de oferta corrente do bem de capital. Ela depende da taxa de retorno que se espera obter do dinheiro investido num bem recentemente produzido" (KEYNES, 1996, p. 149).

${ }^{7}$ Keynes apresenta dois motivos para isso: (1) porque a renda prospectiva baixará conforme suba a oferta desse tipo de capital e (2) porque um aumento na demanda por esse determinado capital ocasionará uma elevação do seu preço de oferta (KEYNES, 1996, p. 150). O autor considera esse segundo motivo o mais importante para estabelecer o equilíbrio de curto prazo, embora o primeiro motivo seja mais importante para o equilíbrio de longo prazo.
} 


\subsection{O Papel da Lucratividade na Acumulação de Capital para a Economia Política Marxiana}

Na economia política marxiana, a lucratividade não é um elemento passivo, mas sim parte central da dinâmica do modo de produção capitalista. O objetivo último de toda produção capitalista é adiantar capital com o intuito de obter lucros, e a capacidade do sistema de gerar lucros em proporção ao capital adiantado é uma variável essencial para a compreensão desse sistema.

Nessa seção apresentamos a concepção de Marx sobre a natureza do lucro, a formação da taxa geral de lucro, a equalização do lucro por meio da concorrência, e a relação entre lucratividade e acumulação de capital. É importante ressaltar que a taxa de lucro apresenta papel relevante também nas demais abordagens de economia política clássica, como em Smith e Ricardo, e que diversos aspectos teóricos da tradição clássica desses autores estão presentes em Marx. Como, a partir da crítica da economia política, Marx inaugura uma nova vertente teórica, trataremos desse autor como a abordagem teórica mais avançada no espectro da tradição clássica.

Nas diversas teorias no escopo da economia política clássica, é comum a centralidade do trabalho na determinação do valor, ou seja, a concepção de que o trabalho é o fundamento da riqueza material e do valor das mercadorias. A partir disso, é também tema central da economia política clássica a distribuição do valor gerado na produção entre as diversas classes sociais e as leis que regem essa distribuição, nas formas salário, lucro e renda da terra. Essa tradição também reconhece a produção de valor excedente e sua distribuição como aspecto fundamental de qualquer sociedade, sendo o excedente o produto além do necessário para reproduzir a classe produtiva.

Marx é o autor que faz a crítica da naturalização das relações capitalistas, buscando demonstrar que é apenas em sociedades capitalistas que a produção de produto excedente assume a forma de valor excedente (mais-valor), com o objetivo converter esse excedente em novo capital e obter continuamente novos excedentes, em escala ampliada. Esse processo é chamado por Marx de acumulação de capital. Assim, no modo de produção capitalista, a produção de riqueza material, ou seja, de mercadorias com valor de uso, tem por finalidade última a obtenção de mais-valor, que é o excedente criado na esfera da produção e realizado na esfera da circulação, a partir da sua venda, e expresso na forma dinheiro. O lucro é a forma aparente da parcela do mais-valor que é apropriada pelos capitais. ${ }^{8}$

Para demonstrar o porquê de o lucro ser a forma aparente do mais-valor, Marx contrapõe a esfera da produção de valor e a aparência do processo de apropriação do valor para o capitalista individual. Partindo do circuito do capital industrial, o valor total das mercadorias produzidas ao final do circuito corresponde à soma do capital constante (c),

\footnotetext{
${ }^{8}$ Segundo Marx, o mais-valor se divide em outras diversas categorias, como juros, alugueis, tributos e renda da terra. Além disso, conforme a metodologia apresentada por Shaikh e Tonak (1994), parte do mais-valor é consumida por setores não produtivos, representando a fonte de salários e lucros nesses setores.
} 
correspondendo ao valor dos meios de produção consumidos no processo de produção, como insumos e máquinas/equipamentos, do capital variável (v), correspondendo ao salário pago pelo trabalho socialmente necessário para a produção das mercadorias, e do mais-valor gerado pelo capital variável (mv), correspondendo ao trabalho excedente criado. Para o capitalista individual, o preço de custo $(\mathrm{k})$ de sua mercadoria corresponde apenas ao capital previamente adiantado para a produção, na forma de insumos e máquinas ou na forma de salários para trabalhadores $(\mathrm{k}=\mathrm{c}+\mathrm{v}) .{ }^{9}$ Por outro lado, o valor adicionado às mercadorias pelo processo de trabalho corresponde à soma do capital variável (salários) e do valor excedente $(\mathrm{v}+\mathrm{mv})$. Logo, o valor total da mercadoria aparece para o capitalista como a soma do preço de custo (k) e de um lucro (l) obtido sobre o valor inicialmente adiantado. Esse lucro é, portanto, a forma aparente do mais-valor criado no processo de produção.

Assim, quando é formado o preço de custo das mercadorias, capital constante e variável são considerados mercadorias homogêneas e igualmente necessárias para o processo de produção. Dessa forma, o mais-valor parece surgir do capital adiantado como um todo (k) e não do trabalho em si, sendo essa forma aparente do mais-valor o que Marx denomina lucro. O lucro aparece como resultado do adiantamento de capital, e não do trabalho excedente.

Lucro é a forma com que se apresenta o mais-valor na superfície do modo de produção capitalista, e esta forma esconde a sua verdadeira fonte. Capital parece ser qualquer valor que se adianta para obter lucros, enquanto o lucro parece ser o rendimento natural de todo o capital, seja capital constante (meio de produção) ou variável (força de trabalho) (GRAZZIOTIN, 2015, p. 77).

A taxa de lucro, por sua vez, é a proporção entre o lucro total obtido e o capital total adiantado, expressando a capacidade do capital de gerar lucros e se valorizar. A taxa de lucro pode ser calculada da seguinte maneira:

$$
l^{\prime}=\frac{m v}{c}=\frac{m v}{c+v}
$$

onde $m v$ é o mais-valor na forma de lucro e $C$ é o capital adiantado na produção, $\mathrm{C}=(\mathrm{c}+\mathrm{v})$, a soma do capital constante e capital variável. Para um capitalista individual, essa relação expressa a taxa de valorização de um único capital, considerando o valor que foi adiantado como capital e o lucro obtido por esse mesmo capital. Quando consideramos o capital social global, ou seja, a agregação de todos os capitais individuais, a medida acima expressa o

\footnotetext{
${ }^{9}$ Isso acontece, já que força de trabalho, no modo de produção capitalista, é considerada uma mercadoria e, portanto, um custo como outro qualquer. Quando o capital variável é considerado um custo tal qual o capital constante, a consequência é o desaparecimento da diferença fundamental que existe entre os dois, de que o primeiro é responsável pela criação de valor.
} 
que Marx chama de taxa geral de lucro, obtida pela proporção entre o mais-valor total gerado pelo capital e o capital social total.

A formação da taxa geral de lucro resulta do processo de equalização da taxa de lucro dos capitalistas individuais. Apesar das possíveis divergências entre taxas de lucro individuais, relacionadas a especificidades de cada setor, para Marx, a força da concorrência obriga os capitalistas a praticarem uma taxa geral de lucro que reflete o lucro médio decorrente dos diversos ramos de produção (MARX, 2013). Como os capitais aplicados nos diversos setores de produção estão em constante concorrência em busca da sua rentabilização, quando um setor oferece taxas de lucro maiores, o efeito é a migração dos capitais menos rentáveis para o negócio mais lucrativo. É o movimento de concorrência entre os capitais que forma a taxa de geral de lucro:

Essa taxa é a taxa média de lucro existente entre os diversos ramos de produção, ponderada pela magnitude do capital aplicado em cada um. Ela existe como uma tendência decorrente do constante movimento dos capitais de um ramo de produção para o outro, ou seja, como tendência criada pela concorrência. O lucro de um capital qualquer que se valoriza de acordo com a taxa geral de lucro é o que Marx chama de lucro médio (GRAZZIOTIN, 2015, p. 80).

Assim, para Marx, a lei fundamental da concorrência capitalista provoca o processo de nivelamento da taxa de lucro individual até a sua equalização como taxa geral de lucro. Há diversos trabalhos empíricos que buscam demonstrar a validade da concepção de concorrência de Marx como um processo turbulento e de constante desequilíbrio em torno de uma taxa de lucro média. ${ }^{10}$ Exemplos são os trabalhos de Maldonado-Filho para o Brasil (1997; 1998), que identificam que não há taxa de lucro significativamente distinta para setores considerados monopolistas, e os dados de Shaikh (2016) para os países da OCDE, ao tratar de concorrência real e de novos investimentos em setores distintos. ${ }^{11}$

Apresentamos sinteticamente até aqui a abordagem de Marx sobre a natureza do lucro e sobre a taxa de lucro como uma medida da capacidade dos capitais manterem o seu processo de valorização. Nessa abordagem, a taxa geral de lucro é a medida de valorização para o capital social global, e entende-se a relevância da análise desta variável a partir da ideia de que o excedente gerado, ou seja, o lucro, necessita de novas aplicações que gerem

\footnotetext{
${ }^{10}$ Para Marx (2013), o processo de nivelação e equalização das taxas de lucro individuais para a taxa geral de lucro é o que explica a diferença dos preços e valores. Os capitais de composição orgânica do capital (c/v) superior tendem a se apropriar de parte do mais-valor que é produzido pelos capitais de composição inferior por meio desse nivelamento. A composição orgânica do capital é a relação entre o valor do capital constante e do capital variável de determinado capital, ou seja, é o componente que reflete a relação técnica entre meios de produção e força de trabalho. Logo, o capital que apresenta uma composição orgânica superior é aquele cuja relação técnica reflete mais capital constante do que capital variável se comparado à composição média do capital social global.

${ }^{11}$ A concepção de equalização de taxa de lucro na teoria de Marx tem base na tradição clássica de nivelamento por constante desequilíbrio, como um processo de gravitação em torno de uma média, e reajuste conforme mudanças ou movimentos inerentes do capital. Essa concepção teórica é fundamentalmente distinta da ideia de equilíbrio de longo prazo neoclássica, onde o equilíbrio é um ponto estacionário.
} 
a sua rentabilidade, como novo capital. Esse processo de aplicação do excedente como novo capital é o processo de acumulação de capital, que resulta na reprodução social em escala ampliada. A relação teórica entre rentabilidade e acumulação é o que trataremos a seguir.

O processo de acumulação de capital na circulação capitalista $\mathrm{D}-\mathrm{M}-\mathrm{D}$ ' pode ser melhor compreendido em comparação com o processo de circulação simples $\left(\mathrm{M}_{1}-\mathrm{D}-\right.$ $\left.\mathrm{M}_{2}\right)$, cujo objetivo é estritamente o consumo de determinado valor de uso $\left(\mathrm{M}_{2}\right)$ distinto do valor de uso inicial $\left(\mathrm{M}_{1}\right)$. Diferentemente da circulação simples, a circulação capitalista não possui um fim definido, pois tanto o seu ponto inicial quanto o seu ponto final são a forma dinheiro, o que, segundo Marx (2012), abre margem para que o ciclo da circulação do capital ocorra de maneira continua.

Nesse processo o capital adquire movimento e consciência própria, sendo o capitalista apenas a sua personificação. O objetivo do capitalista passa a ser não a obtenção de valores ou de um lucro isolado, mas sim a expansão infinita de capital, o interminável processo de obter lucros. Nesse sentido, para Marx, o processo de acumulação infinita de capital não se trata de um comportamento individual e obstinado do capitalista, e sim impulsionado pela concorrência, que o compele a acumular capital para sua reprodução. Trata-se de uma determinação social do modo de produção capitalista que obriga o capital a permanecer em constante movimento de expansão e valorização devido ao desenvolvimento das forças produtivas e à força da concorrência. ${ }^{12}$

O desenvolvimento da produção capitalista torna necessária a elevação contínua do capital empregado num empreendimento industrial, e a concorrência impõe a cada capitalista as leis imanentes do modo capitalista de produção como leis coercitivas externas. Compele-o a expandir continuamente seu capital, para conservá-lo e só pode expandi-lo por meio da acumulação progressiva (MARX, 1998, p. 690).

Logo, compreende-se a relevância da análise da taxa de lucro na economia política marxiana: trata-se de medida relacionada à capacidade de valorização do capital, que é condição para o processo contínuo de acumulação de capital e reprodução em escala ampliada. Baixas taxas de lucro estão relacionadas à menor capacidade de acumulação, gerando entraves na reprodução, e eventualmente crises. Segundo Granados (2012), é possível compreender a dinâmica de crescimento, lucratividade e investimento em Marx a partir da análise dos seus escritos sobre os ciclos.

Os ciclos industriais, mais detalhadamente apresentados em Grazziotin e Herrlein Jr. (2021), são períodos de acumulação de capital que se alternam com o desencadeamento das crises. Marx explica como a taxa de lucro é responsável por liderar o ciclo, portanto

\footnotetext{
${ }^{12}$ A necessidade de acumulação de um capital individual se explica tanto pela necessidade de substituição do capital fixo depreciado, tanto em valor, como em termos tecnológicos, pela necessidade de maior competitividade, redução de custos e de adotar técnicas com maior produtividade. Para o capital individual, esse processo é restrito conforme a demanda existente de determinado ramo de produção. Porém, para o capital social global, por meio do sistema de crédito e da transferência de capital ocioso de determinado ramo para outro por meio de empréstimo, torna-se um processo constante de busca por rentabilidade (MARX, 2014b).
} 
precedendo temporalmente à acumulação de capital ${ }^{13}$. Como a taxa de lucro é o componente dinâmico da economia, uma eventual queda da lucratividade pode ocasionar uma menor acumulação de capital e, consequentemente, uma crise econômica.

Algumas observações quanto à relevância da abordagem da taxa de lucro na economia política marxiana ainda devem ser feitas. Em primeiro lugar, considerar que a lucratividade é uma variável central para a compreensão da análise macroeconômica não significa abandono de outras dinâmicas ou relações de causalidade, como a relevância da demanda, da utilização da capacidade instalada, ou de diferenças e especificidades setoriais, principalmente no curto prazo. A abordagem da lucratividade, embora seja uma abordagem centrada em uma dinâmica estrutural do modo de produção capitalista, também não pode ser considerada uma abordagem determinista, uma vez que a lucratividade depende fundamentalmente de dinâmicas políticas e da luta de classes na distribuição da renda. Trata-se, na verdade, de uma abordagem voltada ao reconhecimento da relevância das condições estruturais do modo de produção capitalista em cada momento, e da ideia de que determinado momento histórico é singular no seu estágio de desenvolvimento das forças produtivas e de sua condição para a reprodução social.

Em segundo lugar, é necessário considerar dois aspectos relevantes para a relação entre lucratividade e acumulação de capital, sendo o primeiro a divisão do mais-valor entre juro e lucro do empresário e seus efeitos para a expansão do capital industrial (MARX, 2014b), e o segundo, a divisão do lucro entre renda do capitalista e fundo de acumulação (MARX, 2014a). Em relação à divisão do mais-valor entre juro e lucro, Marx afirma que o juro corresponde à apropriação de valor por um capital estritamente por seu direito de propriedade, e que quando determinado capital é emprestado na forma de capital de empréstimo, torna-se capital portador de juros, tendo direito a um juro, que corresponde a parte do mais-valor gerado pelo capital industrial posto em circulação, tomador do capital de empréstimo. A taxa de juros, assim, é uma parcela da taxa geral de lucro, sendo o restante a taxa de lucro do empresário. Essa relação, é análoga à concepção de Keynes sobre a relação entre eficiência marginal do capital e juros. Assim como em Keynes, Marx considera que, para o capital individual, alto lucro do empresário é uma motivação para acumulação de capital e expansão da atividade capitalista em determinado setor. No entanto, considerando-se o capital social global, o fato de determinado capital ser aplicado como capital de empréstimo não implica necessariamente que o mesmo foi retirado do circuito de acumulação. Em relação a isso, é necessário considerar que os diversos fundos

\footnotetext{
${ }^{13}$ Uma distinção relevante a ser feita quando tratamos do conceito de acumulação de capital em Marx é a sua abrangência, já que o conceito de investimento mais usual é aquele destinado apenas à aquisição de máquinas e equipamentos. O conceito de acumulação de capital em Marx é mais amplo, já que diz respeito não apenas à aquisição de capital constante, mas também à aquisição de capital variável, isso é, de força de trabalho (GRANADOS, 2012). Capital, para Marx, não se trata de um fator de produção, mas de valores colocados em circulação com o objetivo de obter mais-valor. Além disso, o capital constante compreende não só o que comumente se entende por "capital fixo", mas também matérias-primas, insumos e demais itens necessários para o processo de produção. Nesse sentido, acumular capital não é só ampliar a capacidade produtiva, mas também empregar mais trabalhadores e comprar mais insumos.
} 
monetários que surgem na circulação do capital industrial, assim como os fundos de consumo de trabalhadores e capitalistas, se constituem em fundos monetários para empréstimo do capital bancário, uma vez que estejam na forma de depósitos bancários. Marx retrata como o sistema de crédito, por meio do crédito bancário, permite que capitais fluam para outros setores, permitindo que o processo de equalização de taxas de lucro ocorra de fato (MARX, 2014b). ${ }^{14}$ Assim, o sistema de crédito recoloca os capitais ociosos em circulação no processo de valorização.

O segundo ponto refere-se à divisão do lucro em renda do capitalista e fundo de acumulação. Apesar de o capitalista ser compelido pelas forças da concorrência a acumular, Marx entende que a acumulação de capital para um capital individual consiste em um ato de vontade (MARX, 1998, p. 690). Dessa forma, é necessário que o capitalista defina quanto do mais-valor será destinado para o seu consumo individual, como renda individual, e quanto será destinado para a acumulação de capital. Logo, parte do mais-valor passa a circular como renda do capitalista, e parte circula como novo capital (MARX, 2014a). No entanto, até que haja o dispêndio da renda ou a acumulação de capital, esses valores formam fundos monetários, que também são recolocados no circuito enquanto permanecem na forma de depósitos bancários. Mesmo no caso de busca de rentabilização desses fundos de forma fictícia, como na compra de ações e títulos de dívida pública, que são capitais fictícios, o capital-dinheiro utilizado na compra do título torna-se renda ou capital para o vendedor do título, e permanece disponível para o capital social global por meio do sistema de crédito, enquanto os fundos monetários forem mantidos como depósitos ou enquanto estiverem aplicados como capital em circulação. Então, mesmo que o capital fictício tenha um preço especulativo, que não necessariamente tem fundamento real, o dinheiro utilizado na sua compra ou venda original segue circulando como capital. Dessa maneira, percebese a relevância do sistema de crédito para a concorrência, no nivelamento das taxas de lucro, e na acumulação de capital de forma contínua. Assim, todo o capital-dinheiro disponível é posto à disposição pelo sistema de crédito para acumulação. Isso ocorre ao menos enquanto não há restrição de crédito pelo capital bancário, o que ocorre em fases de crise e superprodução dos ciclos industriais, quando cresce o risco e há incerteza quanto ao retorno dos pagamentos em dinheiro (GRAZZIOTIN e HERRLEIN JR., 2021).

Conforme exposto, Marx apresenta os elementos teóricos para a compreensão da taxa de lucro como uma variável central e determinante para a análise da dinâmica macroeconômica. Como vimos, essa abordagem teórica se diferencia significativamente de outras escolas de pensamento, nas quais a lucratividade é vista como um elemento passivo,

\footnotetext{
${ }^{14}$ Em Grazziotin (2015, p. 170-171), o mecanismo de equalização da taxa de lucro via crédito bancário é explicado da seguinte forma: "a parte do mais-valor destinada à acumulação de capital, ou seja, o fundo de acumulação, só se torna capital-dinheiro de empréstimo se não pode ser aplicado para ampliar a produção. Isso ocorre, em primeiro lugar, se o respectivo ramo de produção já está saturado de capital, e, em segundo lugar, se necessita atingir determinado montante, de acordo com as proporções técnicas exigidas para investir novo capital nesse negócio particular. Ao se tornar capital-dinheiro disponível depositado nos bancos, podem os banqueiros adiantá-lo a outro capitalista, ampliando a produção em outro ramo. Com isso, o capital de um ramo saturado foi aplicado em outro, e este movimento é a própria concorrência entre os capitais, responsável pelo nivelamento da taxa geral de lucro. Dessa forma, o mercado de dinheiro é aí o veículo para esse processo".
} 
que ou está relacionado à remuneração do fator capital conforme a sua escassez, ou à determinação da renda a partir das decisões de gasto.

A partir dessa análise teórica, as próximas duas seções apresentam análises empíricas que demonstram a relevância da análise da taxa de lucro. A primeira compreende a análise histórica das variáveis taxa de lucro e acumulação, medidas a partir das contas nacionais, para a economia brasileira, entre 1953 e 2017. Buscamos descrever essas variáveis, apresentando também os componentes da taxa de lucro conforme a metodologia de análise de decomposição de Weisskopf (1979). A segunda compreende um teste de causalidade de Granger para as séries taxa de lucro e taxa de acumulação apresentadas, buscando testar se há evidência de que a taxa de lucro precede temporalmente a taxa de acumulação de capital.

\section{Evolução da Taxa de Lucro e da Taxa de Acumulação no Brasil (1953- 2017)}

Nesta seção, nosso objetivo é, em primeiro lugar, apresentar a metodologia da decomposição de Weisskopf (1979) para análise da taxa de lucro, que permite, a partir dos dados das contas nacionais, fazer análises empíricas coerentes com a abordagem teórica da economia política marxiana. Em segundo lugar, fazemos uma breve revisão teórica das análises de decomposição da taxa de lucro feitas para o Brasil, em especial os trabalhos de Marquetti, Maldonado-Filho e Lautert (2010) e Marquetti, Hoff e Miebach (2019). Por fim, apresentamos nesta seção uma breve análise da evolução da taxa de acumulação de capital no Brasil.

\subsection{A Análise de Decomposição de Weisskopf (1979)}

A decomposição da taxa de lucro proposta no artigo de Weisskopf (1979) é uma metodologia bastante útil para a análise empírica na economia política marxiana. Basu (2017), ao fazer uma revisão teórica de abordagens quantitativas no escopo da economia política, apresenta a análise de decomposição como uma das principais formas empíricas para análise da taxa de lucro, junto com análises econométricas para testar a lei da queda 
tendencial da taxa de lucro, outro aspecto essencial da teoria de Marx. ${ }^{15}$ Para Basu (2017, p. 1374 , tradução nossa) ${ }^{16}$,

a economia política marxiana entende o capitalismo como um sistema dirigido pela lógica de acumulação de capital. Já que a taxa de lucro é o determinante chave da acumulação de capital, uma extensa literatura marxista se desenvolveu em torno da análise de rentabilidade.

A metodologia apresenta duas vantagens: a primeira é o fato de permitir decompor a taxa de lucro em elementos que representam os seus determinantes teóricos, e analisar separadamente a evolução de cada um desses componentes. Nessa decomposição, a taxa de lucro pode ser explicada por (i) participação dos lucros na renda total, o que representa a disputa entre lucros e salários sobre o valor total criado e reflete a luta de classes entre trabalhadores e capitalistas; (ii) uma medida da utilização da capacidade instalada, como proporção do produto efetivo em relação ao produto potencial, que reflete as condições de demanda, principalmente no curto prazo; e (iii) uma medida da produtividade potencial do capital, como proporção entre o produto potencial e o estoque de capital total, que reflete o desenvolvimento tecnológico e a liberação de mão-de-obra. ${ }^{17} \mathrm{~A}$ abertura nesses três elementos permite análises de curto prazo, com o elemento da demanda representado na capacidade instalada. Para análises de médio e longo prazo, os dois últimos componentes podem ser substituídos pela produtividade efetiva do capital, suprimindo o elemento específico de flutuação de demanda (utilização da capacidade instalada).

Além disso, cada um desses três elementos pode ser decomposto em fatores que representam a variação real, em quantidades, ou variações de preços, permitindo a separação também dessas determinações. Com isso, se cria uma metodologia que permite, por analogia, uma análise da taxa de lucro com base em elementos mensuráveis, o que é a segunda vantagem desta abordagem. São utilizados dados do sistema de contas nacionais para calcular a taxa de lucro e seus componentes, analisando suas variações conforme o

\footnotetext{
${ }^{15}$ Em Basu (2017), o autor busca sintetizar e revisar uma série de abordagens quantitativas no escopo da economia política marxista, mostrando a riqueza teórica recente nessa escola de pensamento. Após análise das controvérsias resultantes do problema da transformação, o autor cita as seguintes abordagens quantitativas recentes nessa tradição: (i) contas nacionais marxianas (Shaikh e Tonak, 1994), em que há a tentativa de estimar as contas nacionais com diferenciação entre setores produtivos e não-produtivos, assim como entre trabalhos considerados produtivos e não-produtivos; (ii) teoria clássica dos preços relativos, com análises sobre as divergências entre preço e valor; (iii) economia política probabilística, com enfoque em distribuições de probabilidade para taxas de lucro em diversos setores; (iv) análise da rentabilidade, com enfoque em análise de decomposição e análise econométrica; e (v) análise de crescimento, distribuição e viés de mudança tecnológica.

16 "Marxian political economy understands capitalism as a system driven by the logic of capital accumulation. Since the rate of profit is a key determinant of capital accumulation, a large Marxist literature has developed around the analysis of profitability [...]".

${ }^{17}$ Utilizamos neste trabalho os termos "produtividade do capital" para o componente $\mathrm{Y} / \mathrm{K}$ ou "produtividade potencial do capital" para o componente $\mathrm{Z} / \mathrm{K}$ a título de simplificação, reconhecendo que esses termos não são rigorosamente coerentes com a teoria marxiana, uma vez que o capital por si só não tem a capacidade de produzir qualquer coisa sem a força de trabalho.
} 
período histórico, políticas econômicas adotadas e a dinâmica da acumulação em cada período. ${ }^{18}$

A decomposição de Weisskopf pode ser apresentada da seguinte forma:

$$
r=\frac{\Pi}{K}=\frac{\Pi}{Y} \cdot \frac{Y}{Z} \cdot \frac{Z}{K}
$$

onde $r$ é a taxa de lucro, medida pela razão entre o lucro total (П) e o estoque de capital (K). $\mathrm{O}$ primeiro elemento da decomposição $(\Pi / \mathrm{Y})$ corresponde à parcela dos lucros na renda, o segundo elemento $(\mathrm{Y} / \mathrm{Z})$ corresponde à razão entre produto efetivo $(\mathrm{Y})$ e produto potencial $(\mathrm{Z})$, representando a utilização da capacidade instalada, e o terceiro elemento $(\mathrm{Z} / \mathrm{K})$ corresponde à relação entre produto potencial e estoque de capital, ou seja, a produtividade potencial do capital.

Weisskopf (1979) utiliza os três componentes para analisar as diferentes teorias de crise de Marx, que afetam a lucratividade. Em relação ao elemento distributivo, quando o crescimento dos salários ou queda da produtividade do trabalho geraria uma pressão nos lucros (profit-squeeze), Weisskopf se refere ao crescimento do poder de barganha dos trabalhadores como explicação para a redução da parcela de lucros e da lucratividade. Em relação ao elemento de demanda, há a referência aos problemas de realização, que seriam responsáveis por reduzir a rentabilidade no curto prazo. Por fim, em relação à tecnologia, Weisskopf se refere ao aumento da composição orgânica do capital, com tecnologias intensivas em capital.

$\mathrm{Na}$ sua versão de médio e longo prazo, a decomposição fica restrita a dois elementos: a parcela de lucros na renda, que representa o conflito distributivo, e a produtividade efetiva do capital, que representa a evolução tecnológica, conforme expressão abaixo. Para o período 1953 a 2017, essa será a forma de decomposição analisada para o caso brasileiro.

$$
\frac{\Pi}{K}=\frac{\Pi}{Y} \cdot \frac{Y}{K}
$$

Algumas observações adicionais são de que as medidas desses componentes são feitas a preços correntes, e que os lucros aqui compreendem todas as rendas de propriedade antes de impostos. Por isso, a soma do lucro total e dos salários $(\mathrm{W})$ corresponde à renda

\footnotetext{
${ }^{18}$ Sobre a utilização dos dados das contas nacionais, é notável que há divergências entre os conceitos aplicados no Sistema de Contas Nacionais e as categorias marxianas, de forma que essas medidas não refletem exatamente o mesmo conceito. É esta a crítica trabalhada em Shaikh e Tonak (1994), que buscam criar uma metodologia de mensuração do produto coerente com a abordagem de Marx. Ao mesmo também, também as medidas propostas por Weisskopf não apresentam correspondência teórica exata com a medida de taxa geral de lucro proposta por Marx, como, por exemplo, o estoque de capital como uma medida do capital total no denominador. Apesar dessas possíveis críticas, as possibilidades empíricas disponibilizadas por essa abordagem são relevantes, e permitem avançar no conhecimento empírico a partir do enfoque na taxa de lucro.
} 
total (Y). A partir disso, pode-se compreender o primeiro componente como uma representação do elemento de conflito distributivo.

$$
\frac{\Pi}{Y}=1-\frac{W}{Y}
$$

ou seja, a parcela dos lucros é inversamente proporcional à parcela dos salários. Quando cresce a parcela dos salários na renda, cai a parcela dos lucros e cai a taxa de lucro, o que está de acordo com a concepção de Marx de que há um conflito distributivo entre essas duas formas de renda. A parcela dos lucros varia conforme o salário médio real ( $\mathrm{W}_{\mathrm{R}}$ ) e a produtividade real do trabalho $\left(\mathrm{y}_{\mathrm{R}}\right)$.

$$
\frac{\Pi}{Y}=1-\frac{w_{R}}{y_{R}}
$$

Isso significa que aumentos do salário médio real em relação à produtividade real do trabalho levam a aumentos da parcela dos salários e redução da parcela dos lucros, e vice-versa. ${ }^{19}$ Por isso, a análise dos períodos em que há divergências entre salário real e produtividade do trabalho é relevante, para verificar as implicações na taxa de lucro por meio de mudanças na parcela de salários e na parcela dos lucros. Períodos de produtividade do trabalho crescendo acima dos salários reais são períodos de crescimento da parcela dos lucros, enquanto períodos de crescimento dos salários reais acima da produtividade do trabalho são de crescimento da parcela dos salários.

Já a produtividade do capital pode ser decomposta em seus elementos de preço e elementos reais, de forma que pode ser expressa pelos preços relativos do estoque de capital em relação aos demais preços e pela produtividade real do capital. Esse último elemento, ao considerarmos tanto numerador como denominador em função do total de trabalhadores (L), expressa também a relação entre a produtividade real média do trabalho e a relação capital real-trabalho $\left(\mathrm{k}_{\mathrm{R}}=\mathrm{K}_{\mathrm{R}} / \mathrm{L}\right)$, que é uma boa medida da composição técnica do capital entre estoque de capital e trabalhadores.

$$
\frac{Y}{K}=\frac{P_{Y}}{P_{K}} \cdot \frac{Y_{R}}{K_{R}}=\frac{P_{Y}}{P_{K}} \cdot \frac{y_{R}}{k_{R}}
$$

A expressão acima mostra que a produtividade do capital cai quando o preço dos bens de capital cresce acima dos demais preços dos produtos, o que demanda mais dinheiro para realizar novos investimentos e aumenta o valor, em termos nominais, do estoque de capital em relação aos produtos. Além disso, a produtividade do capital também cai quando

\footnotetext{
19 Aqui não se trata da relação entre salários reais e produtividade do trabalho proposta pela economia neoclássica, de que o salário real de equilíbrio deve corresponder à produtividade do trabalho, mas sim de reconhecer que a parcela total da renda apropriada na forma de salários depende do crescimento do salário real médio, que representa a parcela da renda real média apropriada por cada trabalhador, em relação à produtividade média do trabalho, que representa a renda real média criada por cada trabalhador.
} 
a composição técnica do capital $\left(\mathrm{k}_{\mathrm{R}}\right)$ cresce em maior proporção ao crescimento da produtividade do trabalho $\left(\mathrm{y}_{\mathrm{R}}\right)$, o que significa que o capital total é composto relativamente por mais máquinas e equipamentos em relação ao número de trabalhadores e que a produtividade do trabalho aumentada por essa nova composição técnica não é suficiente para remunerar o capital em mesma magnitude.

Fazendo a analogia com a forma valor da taxa de lucro apresentada por Marx (2014a), é possível perceber que essas decomposições são coerentes com os principais determinantes teóricos apontados por este autor na evolução da taxa de lucro. Em sua análise sobre à lei da queda tendencial da taxa de lucro, Marx aponta algumas tendências estruturais para a evolução dessa variável ao longo do desenvolvimento capitalista, principalmente associado ao desenvolvimento tecnológico poupador de mão-de-obra e ao aumento gradual da exploração do trabalho. Partindo da relação teórica da taxa de lucro de Marx exposta na seção anterior, ao dividirmos numerador e denominador pelo capital variável (v), temos a seguinte relação:

$$
l^{\prime}=\frac{\frac{m v}{v}}{\frac{c}{v}+\frac{v}{v}}=\frac{m v^{\prime}}{\frac{c}{v}+1}
$$

onde mv' corresponde à taxa de mais-valor, ou seja, a relação de exploração (divisão do valor gerado na jornada média de trabalho entre salários e lucros) e c/v corresponde à composição orgânica do capital, que está relacionada à proporção do capital constante em relação ao capital variável no capital total. Para Marx, o conflito distributivo reflete as variações na taxa de exploração, a partir da distribuição do valor entre salários e lucros, explicada por variações do salário em relação à produtividade do trabalho, conflitos de jornada de trabalho, etc. Por outro lado, o desenvolvimento tecnológico na produção capitalista, embora tenha por objetivo ampliar a produtividade do trabalho, tende também a poupar força de trabalho, elevando a relação c/v no longo prazo. Se a elevação da composição orgânica do capital mais do que compensa o aumento de produtividade, a taxa de lucro tende a cair.

Assim, percebe-se como a decomposição proposta por Weisskopf apresenta aderência à concepção teórica de Marx sobre a taxa de lucro e seus determinantes. A análise da parcela dos lucros e da parcela dos salários capta o conflito distributivo associado à taxa de exploração da força de trabalho, principalmente em relação a diferenças entre salário real e produtividade do trabalho. Já a produtividade do capital capta os efeitos do desenvolvimento tecnológico, seja pelo aumento da produtividade do trabalho, mas também pelo aumento da composição orgânica do capital, que se expressa na proporção K/L. A seguir, apresentaremos os principais trabalhos que analisam a evolução da taxa de lucro para o Brasil, e posteriormente analisaremos a evolução da taxa de acumulação de capital no mesmo período. 


\subsection{Evolução da Taxa de Lucro e de seus determinantes no Brasil (1953- 2017)}

Os principais trabalhos que analisam a macroeconomia brasileira a partir da perspectiva da taxa de lucro aplicando a decomposição de Weisskopf são Marquetti, Maldonado-Filho e Lautert (2010), que analisam o período 1953 a 2003 com uma análise de longo prazo; Marquetti, Hoff e Miebach (2019), que analisam o período 2000 a 2016, em uma análise de curto prazo, e Prado (2017) que aborda as diferentes explicações para a crise brasileira e a relação entre a taxa de lucro e a acumulação do capital. Essa seção tem como objetivo apresentar os dados empíricos já apresentados nesses dois trabalhos e revisar as análises apresentadas nos mesmos, com o intuito de sintetizar os resultados encontrados até aqui para a evolução da taxa de lucro no Brasil. A partir disso, a exposição a seguir se baseia principalmente nesses dois trabalhos.

O Gráfico 1 abaixo apresenta a série de Taxa de Lucro para o Brasil entre 1953 e 2017. A partir desta série, é possível definir alguns recortes temporais considerando períodos de queda e aumento da taxa de lucro, relacionando-os com o contexto econômico e político do Brasil. Em primeiro lugar, conforme ressaltam Marquetti, Maldonado-Filho e Lautert (2010), é notável uma tendência de queda da taxa de lucro de longo prazo de 1953 até 1989 (I, II e III) e depois um período de recomposição dessa taxa, entre 1990 e 2017 (IV).

\section{Gráfico 1 - Taxa de Lucro no Brasil (1953-2017)}

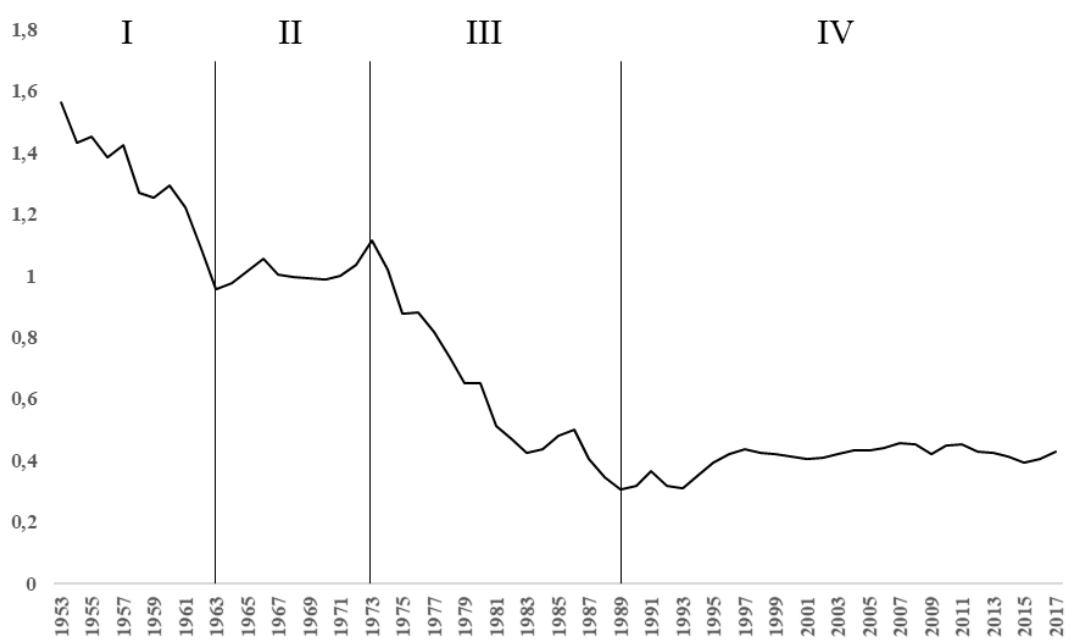

Fonte: Elaboração própria. 
O período de tendência de queda pode ser dividido em três fases: na primeira, entre 1953 e 1962 (I), há um patamar alto de taxa de lucro ao longo da década de 50, no período áureo do processo de substituição de importações (PSI), porém com queda acentuada da taxa de lucro, principalmente entre 1958 e 1962 . O período seguinte (II), de virada na série da taxa de lucro, com crescimento entre 1963 e 1973, coincide com o golpe militar de 1964 e com o chamado período do "milagre econômico" entre 1968 e 1973. Nesse período, a tendência de queda da taxa de lucro é contida por meio das políticas econômicas implementadas, com contenção salarial e mobilização do investimento por meio de estatais, com projetos visando expansão de infraestrutura.

A fase III é de queda significativa da lucratividade entre 1974 e 1989, o que coincide com o período de crise estrutural da economia brasileira. Nesse período há o II PND e o acúmulo de dívida externa, que culminam na crise da dívida dos anos 80, combinando baixo crescimento e forte processo inflacionário. O período posterior (IV), de 1990 a 2017, é o período de instituição de políticas neoliberais, visando crescimento e manutenção da rentabilidade. Pode-se perceber que, nesse último período, a taxa de lucro permanece mais ou menos estável, porém em um patamar bastante inferior ao do início da série.

Os Gráficos 2 e 3 a seguir apresentam a evolução da parcela dos lucros no Brasil e da produtividade do capital para o período de 1953 a 2017. Em relação à parcela dos lucros, percebe-se que a mesma oscila em torno de 50\% e $60 \%$ da renda nesse período, e suas oscilações são coerentes com o resultado das políticas relacionadas a contenção ou expansão dos salários em cada período. Embora, na tradição marxiana, os salários sejam determinados principalmente pelo nível de acumulação de capital, com maior ou menor demanda por trabalho relativamente ao exército industrial de reserva, há também elementos políticos e de disputa de poder na relação distributiva. Já a produtividade do capital representa uma relação técnica, na qual se mede a proporção do valor gerado em relação ao estoque de capital. Como já vimos, essa proporção depende, além dos preços relativos dos bens de capital em relação aos demais preços, da produtividade do trabalho e da relação capital-trabalho, que são medidas da composição orgânica do capital.

No Gráfico 2, é possível perceber que há períodos sucessivos de aumento da parcela dos lucros e posterior queda, formando um processo cíclico de expansão e queda da participação dos lucros na renda total no Brasil. Ao todo, é possível observar três períodos distintos: entre 1955 e 1968, entre 1969 e 1994 e entre 1995 e 2015. 


\section{Gráfico 2 - Parcela dos Lucros no Brasil (1953-2017)}

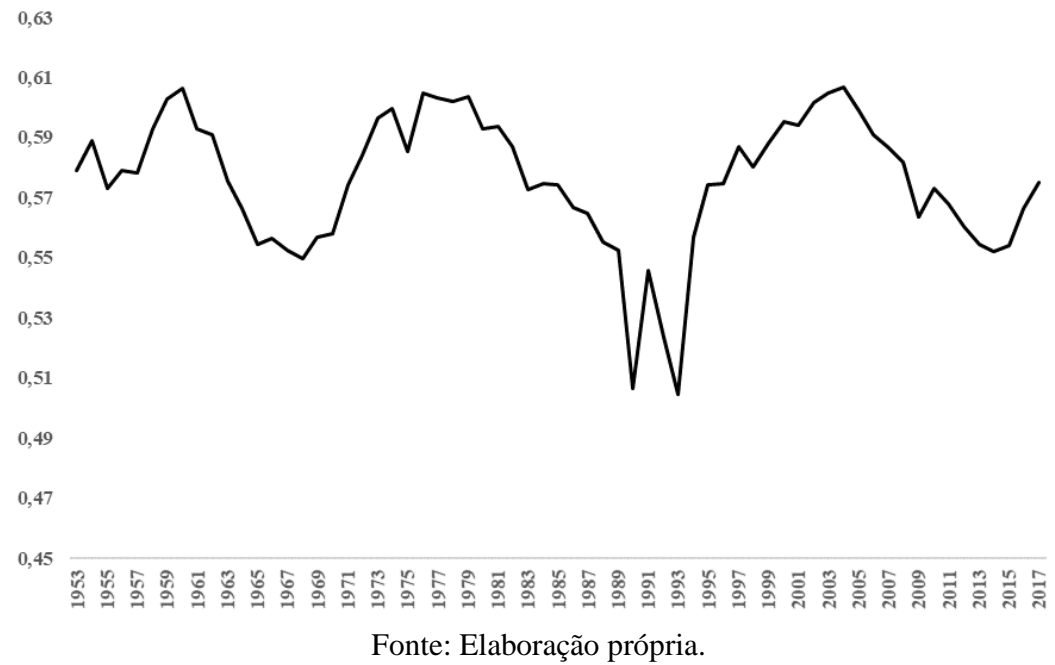

No primeiro período, o aumento da parcela dos lucros ocorre entre 1955 e 1960 , com queda entre 1961 a 1968, período que marca a crise do início dos anos 60 e o golpe militar de 1964, com posterior processo de reformas estruturais (PAEG). O próximo período de expansão da parcela dos lucros se inicia após 1968, o que marca o período do milagre econômico, mas também de contenção salarial e da atividade sindical do período da ditadura militar. A fase de queda da parcela dos lucros se inicia em 1980, e segue até 1994, com efeitos do forte processo inflacionário do período, além da estagnação econômica da década de 80 e do início dos anos 90. A partir de 1995, com o processo de estabilização de preços, pode-se notar a elevação da parcela dos lucros até 2005. A partir de então, com políticas de valorização salarial, a parcela dos lucros passa a cair, mesmo em contexto de crescimento da renda, até 2015.

No Gráfico 3, é possível observar a produtividade do capital para o Brasil no mesmo período. É possível notar que a produtividade do capital tem comportamento bastante semelhante ao da taxa de lucro total, o que denota que este é o principal elemento explicativo das variações da lucratividade no Brasil. Dessa forma, como a parcela dos lucros oscila entre $50 \%$ e $60 \%$ da renda, essas variações afetam o lucro de forma pontual, sendo a trajetória da lucratividade explicada principalmente pela evolução tecnológica expressa na relação entre renda e estoque de capital. 


\section{Gráfico 3 - Produtividade do Capital no Brasil (1953-2017)}

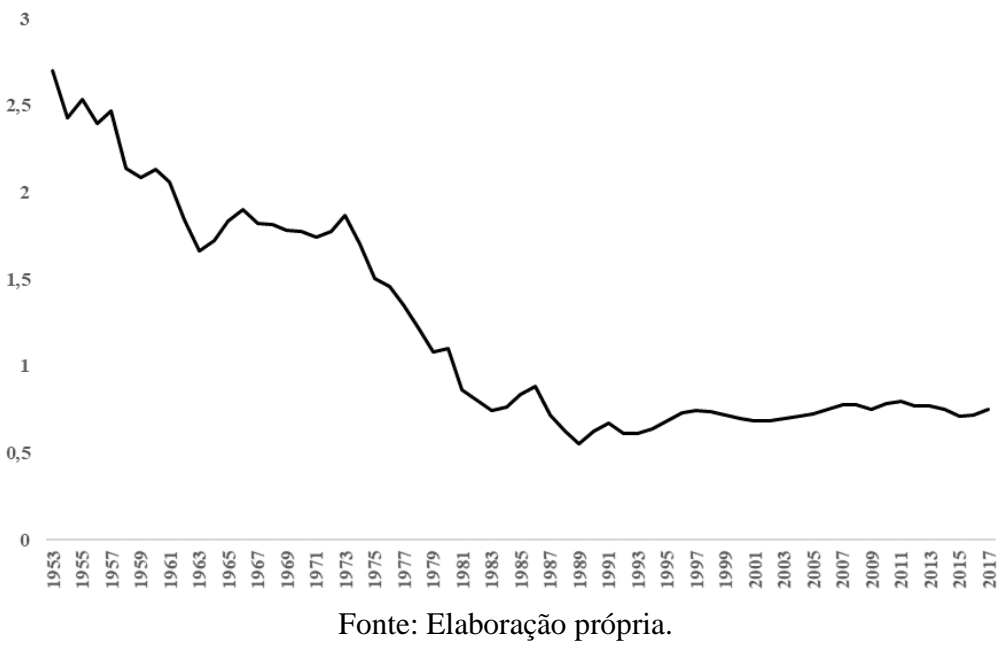

Nota-se que os períodos de queda ou aumento da produtividade do capital coincidem com os da taxa de lucro: queda entre 1953 e 1963, aumento entre 1964 e 1973, porém de forma menos acentuada do que na taxa de lucro, o que se explica pelo aumento da parcela de lucros no período, queda entre 1974 e 1989 e aumento entre 1990 e 2015, mantendo um patamar mais ou menos estável na série.

\subsection{Evolução da Taxa de Acumulação no Brasil (1953-2017)}

Após a apresentação da taxa de lucro e de seus determinantes, é necessário analisar a evolução da taxa de acumulação de capital no Brasil para o período de 1953 a 2017. A taxa de acumulação $(g k)$ se expressa na razão entre o investimento bruto $(I)$ e o estoque líquido de capital fixo $(K)$, representada matematicamente na relação abaixo.

$$
g k=\frac{I}{K}
$$

No que diz respeito à metodologia de cálculo empregada para calcular a série de taxa de acumulação de capital, também são utilizados dados das contas nacionais.

A evolução dessa série e sua análise comparativa com a taxa de lucro permite, em primeiro lugar, compreender a evolução da economia brasileira, relacionando os períodos de aumento ou queda da acumulação de capital com suas fases e, em segundo lugar, analisar o relacionamento dessa variável com a taxa de lucro. Conforme a abordagem da economia política marxiana, maior rentabilidade deve refletir em maior excedente disponível para acumulação, afetando o grau de acumulação de capital, com a conversão desse excedente 
em novo capital, com o objetivo de auferir maiores lucros. A série da taxa de acumulação pode ser observada no Gráfico 4.

Em primeiro lugar, é notável que, assim como a taxa de lucro, a taxa de acumulação apresenta uma tendência declinante de longo prazo. A série evolui de $11 \%$ no seu início para $5 \%$ em 1965 , crescendo a partir dali até 1975 , quando atinge $15 \%$, e depois volta a cair até 1984, quando passa a seguir um patamar de oscilação em torno de 3\% até 2015 , quando cai significativamente e atinge pela primeira vez na série patamares negativos. Nesse sentido, considerando a evolução da taxa de lucro no longo prazo, é possível considerar que há um primeiro padrão coerente entre essas duas séries, de que ambas apresentam um caráter declinante ao longo do tempo, ao menos pelo período considerado nessa análise.

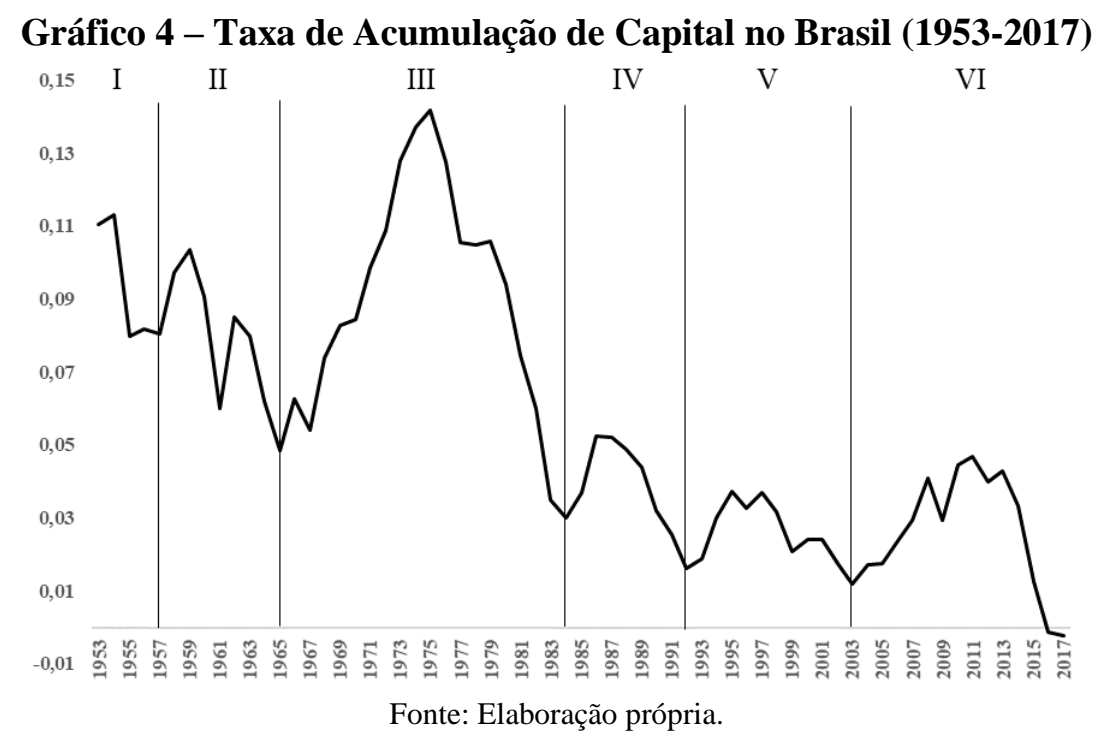

Em segundo lugar, é possível notar na série de taxa de acumulação de capital um padrão cíclico, com períodos sequenciais de aumento da acumulação de capital, seguidos por período de queda. Esses períodos foram destacados graficamente, facilitando a sua visualização, e podem ser descritos em 6 ciclos de acumulação sequenciais a partir dessa série.

O primeiro, de 1953 a 1957, parece ser a fase final de um ciclo anterior, com a fase de queda da taxa de acumulação. No segundo, definido aqui como o período entre 1957 a 1965, com aumento da acumulação no final dos anos 50 e posterior queda, com o período de crise dos inícios dos anos 60. No terceiro, há o maior ciclo de acumulação da série, que se inicia no período da ditadura militar, indo de 1965 até seu pico, em 1975, e queda até 1984. Posteriormente há mais três ciclos, sendo o quarto entre 1984 e 1992, o quinto entre 1992 e 2003 e o sexto e último, entre 2003 e 2017. 
Um último aspecto relevante da série de taxa de acumulação é o fato de que os períodos de crescimento da acumulação de capital são normalmente antecipados por períodos de aumento da taxa de lucro. A próxima seção tem como objetivo apresentar testes econométricos para verificar se há, de fato, uma precedência temporal de aumento da lucratividade para explicar esses períodos de crescimento da acumulação de capital, assim como relacionar a tendência de queda da lucratividade com a tendência de queda da taxa de acumulação.

\section{Análise Empírica da Relação de Causalidade entre Lucratividade e Acumulação}

A economia política marxiana entende a taxa de lucro como motor do modo de produção capitalista, no sentido de expressar a capacidade dos capitais gerarem lucro e se valorizarem, por meio da acumulação de capital. Nessa abordagem, a lucratividade precede temporalmente a transformação desse excedente em novo capital. Nessa seção, apresentamos um teste de causalidade de Granger para as séries de taxa de lucro e taxa de acumulação no Brasil entre 1953 e 2017, para verificar se há precedência temporal entre a taxa de lucro e a taxa de acumulação para o Brasil entre 1953 e 2017. O teste permite analisar se as mudanças de uma variável antecipam os movimentos de outra. Assim, o teste de não-causalidade de Granger permite investigar se existe uma precedência temporal estatisticamente significante que explique o comportamento de uma dada variável. A relevância da análise sobre a relação de causalidade entre lucro e acumulação consiste justamente na importância da compreensão do elemento chave capaz de determinar a variação do ciclo de negócios e crises.

Os resultados apresentados neste artigo são os mesmos de Fornari (2020). Morrone (2015) também realiza esse mesmo teste, porém entre taxa de acumulação de capital e seus componentes, a parcela dos lucros e a produtividade do capital. ${ }^{20}$ Os resultados dos testes empíricos dos dois trabalhos são análogos. ${ }^{21}$

Os testes econométricos desses dois trabalhos foram realizados com base no procedimento desenvolvido por Toda e Yamamoto (1995). Essa escolha se justifica tendo em vista as características das séries utilizadas, sendo a principal o seu tamanho reduzido.

\footnotetext{
${ }^{20}$ Em Morrone (2015), o autor chama a variável (Y/K), que chamamos aqui de "produtividade do capital", como "utilização da capacidade". No entanto, trata-se da mesma variável, de forma que o teste feito pelo mesmo é coerente com os demais resultados apresentados.

${ }^{21}$ Marquetti, Koshiyama e Alencastro (2009) fazem esses mesmos testes para o conjunto de países da OCDE, e encontram resultados consistentes com a abordagem clássico-marxiana para países como Austrália, Dinamarca, EUA, Finlândia e Irlanda, nos quais há evidências de que a taxa de lucro precede a taxa de acumulação e a taxa de investimento. Já para outros países, como Canadá, Coreia do Sul, Grécia e Suécia, há evidência mais consistentes com a abordagem pós-keynesiana, na qual a taxa de investimento, ou seja, a razão entre o investimento e o produto, precede a taxa de lucro.
} 
No caso de Fornari (2020), apresentado em mais detalhe nesse artigo, a amostra apresenta apenas 65 observações. O procedimento padrão para a realização do teste de nãocausalidade de Granger exige que as variáveis sejam estacionárias e não-cointegradas. Para isso, é necessário que se cumpra uma série de etapas antes de proceder o teste de não causalidade de Granger: (1) identificar se a série é estacionária a partir de um teste de raiz unitária; (2) caso tenham raiz unitária, verificar a possibilidade de as séries serem cointegradas a partir de um teste de cointegração como, por exemplo, o teste de Johansen, ou então verificando a não-estacionariedade dos resíduos das variáveis por meio de um teste de raiz unitária.

Diferentemente do procedimento convencional para o teste de não-causalidade de Granger, o método de Toda e Yamamoto permite a utilização de séries com diferentes ordens de integração, assim como séries cointegradas ou não cointegradas. Além do mais, esse procedimento é o mais recomendado para séries com amostras relativamente pequenas. A contribuição de Toda e Yamamoto (1995) foi demonstrar que o teste de Wald permite verificar a hipótese de não causalidade quando são testadas restrições nos parâmetros de um modelo VAR, independente da condição de integração ou cointegração das variáveis, que apresentam uma distribuição assimptótica qui-quadrado $\left(\chi^{2}\right)$.

O teste é aplicado para verificar as restrições dos parâmetros de um modelo VAR $\left(k+e_{\text {max }}\right)$ aumentado em níveis e estimado por mínimos quadrados ordinários (MQO). A estimação do $\operatorname{VAR}\left(k+e_{\max }\right)$ consiste no somatório do número ótimo de defasagens, k, e na ordem máxima de integração das séries, $e_{\text {max }}$. Sendo assim, com o objetivo de seguir o recomendado pelo método mencionado acima, o teste pode ser realizado procedendo com as seguintes etapas:

1. aplicação dos testes de raiz unitária para definir a ordem máxima de integração do sistema ( $\left.e_{\max }\right)$

2. escolha do número ótimo de defasagens $(\mathrm{k})$ a partir do critério de informação de Akaike (AIC);

3. estimativa de um VAR $\left(k+e_{\max }\right)$ em níveis, conforme o especificado pelas equações abaixo:

$$
\begin{aligned}
& (g k)_{a}=c_{1}+a_{1 j} \sum_{j=1}^{k}(g k) a j+\delta_{1} \sum_{j=1}^{k}(r)_{a j}+\tau_{1 t} \\
& (r)_{a}=c_{2}+a_{2 j} \sum_{j=1}^{k}(g k) a j+\delta_{2} \sum_{j=1}^{k}(r)_{a j}+\tau_{2 t}
\end{aligned}
$$

onde $g k$ representa a taxa de acumulação e $r$ representa a taxa de lucro.

(4) aplicação do teste de restrições de Wald nos $z$ primeiros coeficientes, a fim de testar a hipótese de não-causalidade de Granger.

A hipótese de não-causalidade de Granger para o teste de restrição de Wald deve ser analisada da seguinte forma: a taxa de acumulação "Granger causa" a taxa de lucro 
quando a hipótese $H_{0:} a_{1 j}=0$ é rejeitada; por outro lado, se a taxa de lucro "Granger causa" a taxa de acumulação, a hipótese $H_{0:} \delta_{1 j}=0$ deve ser rejeitada.

Os resultados encontrados para cada uma das etapas exigidas pelo método de Toda e Yamamoto em Fornari (2020), com a finalidade de discutir a possível relação empírica de causalidade encontrada entre as variáveis, podem ser visualizados a seguir. O primeiro passo consiste em analisar o efeito do tempo nas séries históricas da taxa de lucro $(r)$ e taxa de acumulação de capital $(g k)$ por meio do teste de raiz unitária Dickey Fuller aumentado (ADF). Conforme a Tabela 1 , é rejeitada a hipótese nula de raiz unitária para a variável taxa de lucro no nível e sem constante.

No entanto, tendo em vista que os demais testes no nível aceitam $H_{0}$, é prudente concluir que a série é integrada de ordem um, I(1). Em relação à taxa de acumulação de capital, o resultado do teste foi de que a série pode ser considerada integrada de ordem um, I(1), uma vez que a variável apresentou raiz unitária para todos os testes realizados no nível e houve rejeição de $H_{0}$ na primeira diferença. Com isso, define-se que a ordem máxima de integração do sistema em questão é igual a um, $e_{\max }=1$.

Tabela 1 - Teste de raiz unitária para as variáveis da regressão

\begin{tabular}{ccccc}
\hline \hline Variável & Modalidade do teste & Ordem de integração $\left(e_{\text {max }}\right) *$ & ADF & p-valor \\
\hline & Sem constante & 0 & $-3,76$ & $0,0003 * * *$ \\
& Com constante & 0 & $-2,89$ & 0,0511 \\
Taxa de lucro $(r)$ & Com constante e tendência & 0 & $-1,37$ & 0,8595 \\
& Sem constante & 1 & $-6,49$ & $0,00^{* * *}$ \\
& Com constante & 1 & $-6,86$ & $0,00^{* * *}$ \\
& Com constante e tendência & 1 & $-7,21$ & $0,00^{* *}$ \\
\hline \multirow{3}{*}{ Taxa de acumulação } & Sem constante & 0 & $-1,68$ & 0,0869 \\
de capital $(g \mathrm{k})$ & Com constante & 0 & $-1,62$ & 0,4656 \\
& Comstante e tendência & 0 & $-2,48$ & 0,3352 \\
& Sem constante & 1 & $-6,52$ & $0,00 * * *$ \\
& Com constante & 1 & $-6,59$ & $0,00 * * *$ \\
& Com constante e tendência & 1 & $-6,53$ & $0,00 * * *$ \\
\hline \hline
\end{tabular}

Fonte: Fornari (2020).

Nota: $(*) e_{\max }$ foi determinado a partir do teste de Dickey-Fuller aumentado (ADF)

Feito isso, o segundo passo é estimar um VAR (3) para cada uma das variáveis, com o objetivo de analisar qual seria o número de defasagens capaz de minimizar o critério de Akaike (AIC). Para a variável taxa de acumulação, o número de defasagens que minimiza o critério de Akaike é de duas defasagens, enquanto que, para a variável taxa de lucro, é de três. Dessa forma, o número ideal de defasagens para o sistema é $\mathrm{k}=3$. O resultado desse procedimento pode ser verificado na Tabela 2 . 
Tabela 2 - Número de defasagens (k)

\begin{tabular}{ccc}
\hline \hline Variáveis & VAR (3) & Número de defasagens (k) \\
\hline Taxa de lucro $(r)$ & $-3,239305^{*}$ & 3 \\
Taxa de acumulação $(g k)$ & $-6,035673^{*}$ & 2 \\
\hline \hline
\end{tabular}

Fonte: Fornari (2020)

Nota: $\mathrm{O}$ número de defasagens $(\mathrm{k})$ foi definido a partir do

Critério de Informação de Akaike (AIC).

Tendo em vista que a ordem de integração máxima do sistema obtida é $e_{\max }=1$ e o número de defasagens ideal é $\mathrm{k}=3$, logo o Vetor Auto Regressivo recomendado pela metodologia de Toda e Yamamoto (1995) para testar a hipótese de não causalidade de Granger é o VAR (3+1), ou seja, um VAR (4). Feito isso, realiza-se o teste de restrições de Wald em níveis para os k primeiros parâmetros com o objetivo de testar a hipótese de não causalidade de Granger. Os resultados para esse procedimento podem ser observados nas Tabelas 3 e 4.

Tabela 3 - Teste de Wald para a hipótese $(g k \rightarrow r)$

\begin{tabular}{cccc}
\hline \hline Testes & Valores & Graus de liberdade (df) & Probabilidade \\
\hline Teste-F & 0,278254 & 3,52 & 0,8408 \\
\hline Qui-quadrado & 0,834762 & 3 & 0,8411 \\
\hline \hline & &
\end{tabular}

Tabela 4 - Teste de Wald para a hipótese $(r \rightarrow g k)$

\begin{tabular}{cccc}
\hline \hline Testes & Valores & Graus de liberdade (df) & Probabilidade \\
\hline Teste-F & 7,933975 & 3,52 & 0,0002 \\
\hline Chi-quadrado $\left(\chi^{2}\right)$ & 23,80193 & 3 & 0,0000 \\
\hline \hline
\end{tabular}

Fonte: Fornari (2020)

O resultado da Tabela 3 indica que, em primeiro lugar, não é possível rejeitar a hipótese de que a taxa de acumulação não Granger causa a taxa de lucro, de forma que o teste permite concluir que a taxa de acumulação não precede a lucratividade. Na Tabela 4, a hipótese nula, $H_{0:} \delta_{1 j}=0$, ou seja, de que a taxa de lucro não "Granger causa" a taxa de acumulação, é rejeitada com elevada significância estatística. Com isso, os resultados em Fornari (2020) permitem perceber que, para o caso brasileiro, o teste é coerente com a abordagem teórica clássico-marxiana. Os testes sugerem que a taxa de lucro precede temporalmente a taxa de acumulação, antecipando as suas variações, o que corrobora 
empiricamente a interpretação teórica marxista de que a lucratividade é o motor da acumulação de capital.

Já Morrone (2015) realiza o mesmo teste considerando os componentes da taxa de lucro, ou seja, a parcela dos lucros $(\Pi / Y)$ e a produtividade do capital $(Y / K)$. A metodologia de cálculo também é o procedimento de Toda e Yamamoto, e os resultados são análogos aos encontrados em Fornari (2020). Nos testes de Morrone (2015), há rejeição da hipótese nula para o teste de não-causalidade entre a produtividade do capital $(Y / K)$ e a taxa de acumulação, de forma que as variações desse componente precedem as variações da taxa de acumulação. Não é possível rejeitar a hipótese nula de não-causalidade para a parcela dos lucros, de forma que não é possível afirmar que o componente distributivo entre salários e lucros representa precedência temporal em relação à acumulação. Dessa forma, o componente tecnológico da taxa de lucro, que considera a produtividade do trabalho e a composição do capital entre estoque de capital e trabalhadores (relação $K / L$ ) que é o elemento determinante da acumulação, a partir dos testes em Morrone (2015).

Dessa forma, temos dois trabalhos que sustentam que, para as séries calculadas de taxa de lucro e de taxa de acumulação no Brasil, é possível afirmar que há precedência temporal da lucratividade em relação à acumulação. Assim, o estudo da lucratividade permite compreender e antecipar momentos do ciclo econômico, e também compreender a conjuntura econômica. Esses resultados corroboram a relevância das análises históricas apresentadas anteriormente para a taxa de lucro no Brasil, e da relevância dessa abordagem na interpretação dos diversos momentos históricos na economia brasileira.

\section{Conclusões}

Nesse trabalho analisamos teórica e empiricamente a relação entre a lucratividade e acumulação de capital no Brasil. Para a economia política marxiana, a abordagem da taxa de lucro é fundamental na compreensão da dinâmica de economias capitalistas. Há literatura significativa nesta abordagem para o caso brasileiro, permitindo compreensão dos diferentes momentos da economia brasileira e de seus limites estruturais. Este trabalho sintetiza algumas contribuições desta abordagem, além de apresentar novas evidências empíricas relacionadas à centralidade da taxa de lucro.

Fizemos inicialmente uma exposição das concepções teóricas de diferentes escolas de pensamento econômico em relação ao lucro, comparando aquelas em que a rentabilidade é um elemento passivo, resultante de outras variáveis ou dinâmicas econômicas, daquelas em que o lucro apresenta papel central e determinante, como variável-chave para compreensão da dinâmica capitalista. Como escolas que compreendem o lucro como elemento passivo, apresentamos a concepção neoclássica do lucro, fundamentada na teoria 
da distribuição dos rendimentos de J.B. Clark, e a concepção keynesiana de que o lucro é resultado das decisões de gasto.

Na visão neoclássica, o lucro (ou o juro sobre o capital próprio) se explica como rendimento do capital enquanto fator de produção, assim como os salários são rendimentos do fator de produção trabalho. Tanto lucro e salário, em um contexto de concorrência e maximização de lucros, são equivalentes à produtividade marginal do fator de produção, de forma que haja a plena alocação desses fatores. Assim, o lucro funciona como uma sinalização para a efetiva alocação do capital em diversos setores. Em equilíbrio, não há lucro acima do juro sobre capital próprio, entendido como a remuneração normal do fator de produção capital. Esse rendimento do capital, na concepção neoclássica, já é considerado como parte do custo de oportunidade de utilização do capital, de forma que custos e receitas, em equilíbrio, se equivalem, não existindo um excedente. Essa concepção, dessa forma, sustenta a visão de que cada fator de produção recebe a remuneração equivalente ao que contribui na produção, e não há qualquer excedente ou expropriação em economias de mercado em equilíbrio.

Já na concepção keynesiana, embora diversos dos elementos da concepção neoclássica sejam implicitamente aceitos sobre o lucro, há a concepção de que a renda e o equilíbrio não dependem estritamente da alocação efetiva dos recursos, mas das decisões de gasto, que levam a decisões de emprego ou investimento, conforme as expectativas dos agentes econômicos e maior ou menor preferência pela liquidez. Assim, a renda total é determinada pelas decisões de gasto, e ela, por sua vez, determina o lucro total e a lucratividade. A expectativa de lucro, um elemento subjetivo, aparece na teoria keynesiana como a eficiência marginal do capital e, em comparação com a taxa de juros corrente, é o fator determinante para as decisões de gasto. Assim, a concepção keynesiana coloca a expectativa e a decisão de gasto como elemento anterior ao nível de lucros e à rentabilidade.

De forma distinta em relação a essas duas abordagens, a economia clássica, especialmente em sua vertente marxiana, reconhece a necessidade de se considerar o lucro e a rentabilidade como variáveis-chave da dinâmica capitalista. O lucro é o excedente gerado no processo de valorização do capital, como mais-valor apropriado pelos capitais no processo de produção. Nessa concepção, o valor tem seu fundamento no trabalho, e o lucro é o excedente gerado para além da reprodução da classe produtiva, ou seja, a classe trabalhadora no modo de produção capitalista. Esse excedente, pelo imperativo da concorrência, torna-se novo capital no processo contínuo de acumulação e rentabilização do capital total. Por meio do sistema de crédito, o capital ocioso se distribui entre os diversos ramos capitalistas. Esse processo gera equalização das taxas de lucro, uma vez que o capital pode se mover entre diversos ramos de produção, conforme diferenciais de rentabilidade. Assim, a taxa geral de lucro representa uma medida da geração de excedente em relação ao capital total. Sua evolução permite compreender a capacidade da economia capitalista em acumular esse novo excedente, transformando-o em novo capital.

Posteriormente, apresentamos a metodologia de Weisskopf para análise da taxa de lucro e de sua decomposição, que é bastante utilizada no escopo da economia política marxiana para analisar e compreender a dinâmica macroeconômica com base na taxa de 
lucro. Mostramos como a taxa de lucro pode ser decomposta entre parcela dos lucros, utilização da capacidade instalada e produtividade do capital. Além disso, demonstramos como a parcela dos lucros é inversamente proporcional à parcela dos salários, uma vez que há um conflito distributivo entre salários e lucros, e que a parcela dos salários depende da produtividade do trabalho e do salário real médio. Em relação à produtividade do capital, demonstramos que a mesma depende dos preços relativos dos bens de capital em relação aos demais preços, da produtividade do trabalho e da relação capital-trabalho, o que corresponde à concepção de Marx sobre desenvolvimento tecnológico e composição orgânica do capital.

Após explicitarmos essa metodologia, útil para análises empíricas, apresentamos as séries calculadas da taxa de lucro, parcela dos lucros na renda, da produtividade de capital e da taxa de acumulação para o Brasil, entre o período de 1953 a 2017, com uma breve análise histórica da sua evolução e de seus determinantes. Observamos que a taxa de lucro apresenta tendência declinante para o período na economia brasileira, com períodos de aumento e recomposição da rentabilidade. A parcela dos lucros oscila entre $50 \%$ e $60 \%$ da renda total, com períodos de aumento e queda sucessivos, conforme evolução das disputas entre lucros e salários, porém o principal elemento explicativo da taxa de lucro é a produtividade do capital, que corresponde ao desenvolvimento tecnológico. A taxa de acumulação, por sua vez, também apresenta tendência declinante no período, e apresenta ciclos sucessivos de crescimento e queda da acumulação de capital, com os momentos de crescimento antecipados por aumento da taxa de lucro.

Por fim, apresentamos testes econométricos para testar a relação de causalidade entre as séries de taxa de lucro e da taxa de acumulação, buscando verificar se é possível que uma das séries tenha precedência temporal em relação à outra. A metodologia utilizada foi o procedimento proposto por Toda e Yamamoto, para realização de um teste de causalidade de Granger para séries com baixo número de observações. O resultado é de que há rejeição da hipótese nula de que taxa de lucro não Granger causa taxa de acumulação para o Brasil nesse período, de forma que temos uma evidência empírica coerente com a abordagem da economia política marxiana.

A partir deste trabalho, demonstramos, com argumentos teóricos e empíricos, a relevância da abordagem da taxa de lucro na compreensão da dinâmica macroeconômica. Para o caso brasileiro, a literatura é robusta em termos de análise e de interpretações sobre a evolução da economia brasileira. Nesse sentido, trata-se de uma escola de pensamento rica para novas frentes de pesquisa e de investigação.

\section{Referências}

BASU, D.; MANOLAKOS, T. Is There a Tendency for the Rate of Profit to Fall? Econometric Evidence for the U.S. Economy, 1948-2007. Review of Radical Political Economics, v.45 n.1 p.76-95, 2012. DOI: https://doi.org/10.1177/0486613412447059 
BASU, D.; VASUDEVAN, R. Technology, distribution and the rate of profit in the US economy: understanding the current crisis. Cambridge Journal of Economics, n. 37 p.5789, 2012. DOI: https://doi.org/10.1093/cje/bes035

BASU, D; DAS, D. Profitability and investment: evidence from India's organized manufacturing sector. Metroeconomica, vol. 68, n. 1, 2016. DOI: https://doi.org/10.1111/meca.12126

BASU, D. A Selective Review of Recent Quantitative Empirical Research in Marxist Political Economy. Journal of Economic Surveys. v. 31, n. 5, p. 1359-1386, 2017. DOI: https://doi.org/10.1111/joes.12218

DUMENIL, G; LEVY. D. The Economics of the Profit Rate. Aldershot: Edward Elgar, 1993.

DUMENIL, G; LEVY. D. Being keynesian in the short term and classical in the long term: the traverse to classical long-term equilibrium. The Manchester School. v. 67 n.6, p. 684716, 1999. DOI: https://doi.org/10.1111/1467-9957.00175

FORNARI, A. P. Investimento e Lucratividade no Brasil: uma análise a partir do teste de causalidade de Granger (1955-2017). Porto Alegre: PUCRS, 2020. (Monografia).

GRANADOS, J. T. Does investment call the tune? Empirical evidence and endogenous theories of the business cycle. [S.I.]: Research in Political Economy, 2012.

GRAZZIOTIN, Henrique de A. Sistema de crédito, ciclos industriais e institucionalidade financeira: uma sistematização da teoria monetária e financeira de Marx. Porto Alegre: UFRGS, 2015. (Dissertação)

GRAZZIOTIN, H. A.; HERRLEIN JR. R. Sistema de crédito e crises em Marx: o ciclo industrial e as suas fases. Economia e Sociedade, Campinas, v. 30, n. 1 (71), p. 39-62, janeiro-abril, 2021.

HUNT, E.K., LAUTZENHEISER, M. História do Pensamento Econômico. Tradução de André Arruda Vilela. Rio de Janeiro: Elsevier, 2013.

KEYNES, John M. A Teoria Geral do Emprego, do Juro e da Moeda. Tradução do texto The General Theory of Employment, Interest and Money Royal Economic Society, 1973. São Paulo: Editora Nova Cultural, 1996.

MALDONADO-FILHO, Eduardo. The Circuit of Industrial Capital, Price Changes and the Profit Rate. In: conference of the Eastern Economic Association (available at http://www.greenwwich.ac.uk/ fa03). 1997.

MALDONADO-FILHO, Eduardo. Competition and equalization of inter-industry profit rates: the evidence for the Brazilian economy, 1973-85. International Working Group on Value Theory miniconference at the Eastern Economic Association, 1998. 
MARQUETTI, A.; KOSHIYAMA D.; ALENCASTRO D. O aumento da lucratividade expande a acumulação de capital? Uma análise da causalidade de Granger para os países da OCDE. Rio de Janeiro: Revista Economia Contemporânea, 2009.

MARQUETTI, A.; MALDONADO, E.; LAUTERT, V. The profit rate in Brazil, 19532003. Review of Radical Political Economics. v. 42 n.4 p. 485-504, 2010. DOI: https://doi.org/10.1177/0486613410375058

MARQUETTI, A.; HOFF, C.; MIEBACH, A. Profitability and Distribution: The Origin of the Brazilian Economic and Political Crisis. Latin American Perspectives. v. 47 n.1, 2020. DOI: https://doi.org/10.1177/0094582X19887751

MARQUETTI, A. et. al. Measuring the Profit Rate in an Inflationary Context: The Case of Brazil, 1955-2008. Review of Radical Political Economics. v. 51 n.1 p. 52-74, 2019. DOI: https://doi.org/10.1177/0486613416689834

MARX, K. O Capital: crítica da economia política. Livro I - O processo de produção do Capital. Volume 1. 30. ed. Rio de Janeiro: Civilização Brasileira, 2012.

O Capital: crítica da economia política. Livro I - O processo de produção do Capital. Volume 2. 16. ed. Rio de Janeiro: Civilização Brasileira, 1998.

O Capital: crítica da economia política. Livro II - O processo de circulação do Capital. Volume 3. Rio de Janeiro: Civilização Brasileira. 14 ${ }^{\mathrm{a}}$ Ed. 2014a. 598 p.

O Capital: crítica da economia política. Livro III - O processo global de produção capitalista. Volume 4. Rio de Janeiro: Civilização Brasileira. 2013.

O Capital: crítica da economia política. Livro III - O processo global de produção capitalista. Volume 5. 2. ed. Rio de Janeiro: Civilização Brasileira, 2014b.

Grundrisse: manuscritos econômicos de 1857-1858. São Paulo: Boitempo, 2011.

MORRONE, H. Do demand and profitability stimulate capital accumulation? An analysis for Brazil. Cepal Review, n. 116, 2015.

PRADO, E. Das explicações para a quase estagnação da economia capitalista no Brasil. Revista de Economia Política, v. 37, n. 3, 2017.

SHAIKH, A.; TONAK, E. Measuring the Wealth of Nations: The Political Economy of National Accounts. Cambridge: Cambridge University Press. 1994

SHAIKH, A. The first great depression on the $21^{\text {st }}$ century. Socialist Register, 2011.

SHAIKH, A. Capitalism: competition, conflict, crises. Oxford University Press, 2016.

TODA H.; YAMAMOTO, T. Statistical inference in vector autoregressions with possibly integrated processes. Journal of Econometrics, n. 66, 1995. DOI: https://doi.org/10.1016/0304-4076(94)01616-8 
WEISSKOPF, T. Marxian crisis theory and rate of profit in the postwar US economy. Cambridge Journal of Economics, v. 3, n. 4, 1979. 